\begin{tabular}{lllll}
$\begin{array}{l}\text { Abstract G100(P) Table } 1 \\
\text { breaks? }\end{array}$ & How regularly are you taking your \\
\hline & $\begin{array}{l}\text { Pre- } \\
\text { Conference }\end{array}$ & $\begin{array}{l}\text { Post } \\
\text { Conference }\end{array}$ & $\begin{array}{l}\text { July } \\
2019\end{array}$ & $\begin{array}{l}\text { October } \\
2019\end{array}$ \\
\hline & $44 \%$ & $87 \%$ & $59 \%$ & TBC \\
\hline $\begin{array}{l}\text { Always/Mostly Taking a Break } \\
\text { Sometimes/Occasionally/Never }\end{array}$ & $56 \%$ & $13 \%$ & $41 \%$ & TBC \\
\begin{tabular}{l} 
Taking a Break \\
\hline
\end{tabular} & & & & \\
\hline
\end{tabular}

pressure was also an issue 'the squeeze'. 'Unexpected work' and 'lack of wiggle room' alongside 'staffing shortages' made planning difficult. 'Peer pressure' to keep working and 'not being seen as a human being' with a sense of 'personal guilt' need to be addressed.

Environment: 'nice staff room' and 'ability to hand bleep over' with 'scheduling breaks as a team'. Leaders also need to role model alongside 'giving yourself permission'. We all need to find 'courage to have break uninterrupted'.

Discussion Our workshop shows there are barriers and enablers to taking a break. Changes are needed as individuals but more importantly as teams and organisations to enable all colleagues to feel empowered to take their breaks. Our workshop has shown an improvement in number of colleagues taking a break. We are now planning the next stage to roll out wider.

\section{G101(P) TEAM EQUIP (EDUCATION IN QUALITY IMPROVEMENT IN PAEDIATRICS)}

SJ Gray.

\subsection{6/archdischild-2020-rcpch.80}

\section{Background}

- No previous team-based multi-disciplinary Quality Improvement (QI) training package in child health in region

- Huge appetite for change across city/trust - bid made to Health Education England

\section{Aim}

- To deliver a 1-year QI programme to groups of multidisciplinary professionals working across child health in city and facilitate group project work-streams (minimum of 8) utilising these QI skills to deliver specific, measurable, achievable, realistic improvements within the year.

Process

- All groups working with children invited across hospital trust \& primary care

- 15 Team EQUIP sessions organised with standardised structure

- First part: Introduction to QI and methodology

- Second part: Interactive project planning (brainstorming areas for improvement, dot voting \& Pareto charting to decide on project(s) followed by driver diagram, process mapping, generating SMART aim \& initial stage planning)

\section{Outcome Measures}

- Pre- and post-course questionnaire relating to knowledge, interest and involvement in QI

- Variable measures for different work-streams

\section{Results}

- 64 attended sessions with improvement in knowledge, interest and likelihood to get involved
- 19 work-streams in progress spanning a wide array of improvement areas relating to child health

\section{Learning Points}

- Running a programme like this single-handedly is massively time consuming but good for quality control

- NHS work pressures are over-whelming (2 sessions cancelled last minute by day surgery and one of the GP teams)

- Incentives (free lunch, prizes, conference funding) work

- Facilitating self-directed projects works wonders for engagement $\&$ motivation for the vast majority (but not all!)

Next Steps

- Supporting ongoing projects \& dissemination via poster production, conference presentations \& publication

- Spread learning \& experience to other specialties through trust-wide QI steering group \& for child health regionally via regional QI network, Q network \& nationally through $\mathrm{RCPCH}$ conference \& RCPCH QI Central

\section{G103(P) QUALITY IMPROVEMENT PROJECT ON HANDOVER SESSIONS IN THE PAEDIATRIC DEPARTMENT OF A DISTRICT GENERAL HOSPITAL}

C Orazulume, L MacKinnon. Paediatrics, Peterborough City Hospital, Peterborough, UK

\subsection{6/archdischild-2020-rcpch.81}

Aims The aims of this project were to improve the quality of morning handover, making them succinct but effective and ensuring they provided learning opportunities for trainees.

Methods We handed out questionnaires to staff in the paediatric department, at random, to conduct a survey. The questionnaire comprised of 11 positive statements about the handover, which they had to qualify as either 'strongly disagree', 'disagree', 'neither agree or disagree', 'agree', 'strongly agree' or 'don't know'. In the first phase (pre-intervention) we gathered their initial responses to these statements. We then introduced our 7-step handover guide (adapted from the $\mathrm{RCPCH}$ handover assessment tool), which was used at every morning handover for 1 month. The staff's opinions on these statements were then re-evaluated using the same questionnaire (postintervention phase).

Results The percentage of staff who answered 'agree' or 'strongly agree' increased after the intervention for 9 out of the 11 positive statements about handover. It was only 'clarity about the most unwell patients at the end of handover' and 'handovers are enjoyable and non-intimidating' that yielded worse results after the intervention.

\section{Questionnaire statements:}

1. The handovers are well structured

2. I feel well-informed about the patients at the end of the handover

3. It is clear who the most unwell patients are at the end of handover

4. I am aware of all the patients with safe-guarding or child protection issues by the end of handover

5. Patients with similar names are clearly identified

6. Important safety issues are highlighted during handover e.g. patients with severe allergies, equipment issues etc.

7. Infection control issues are identified e.g. patients with RSV

8. It is clear which staff are rostered on for the day and whether there are rota gaps 